\title{
Impact of Friction Stir Processing Parameters on Forming the Structure and Properties in AISI 420 Steel Surface Layer
}

\author{
V.V. Voropaev¹, V. P. Kuznetsov¹,2, A. S. Skorobogatov¹, and A.A. ${ }^{1}$ Barashova ${ }^{1}$ \\ ${ }^{1}$ Yeltsin Ural Federal University, Yekaterinburg, Russia \\ ${ }^{2}$ M.N. Mikheev Institute of Metal Physics, the Ural Branch of the Russian Academy of Sciences, \\ Yekaterinburg, Russia
}

\section{Abstract}

Research has been done into the influence of friction thermomechanical treatment parameters on forming the structure and properties in a surface layer of $20 \times 13$ steel. The paper presents a theoretical approach towards controlling the process variables. A hardened layer with a thickness of 1,7 mm was obtained after $20 \times 13$ steel had been

Corresponding Author: V.V. Voropaev sen_vvv@mail.ru

Received: 25 February 2019 Accepted: 9 April 2019 Published: 15 April 2019

Publishing services provided by Knowledge E

(c) V.V. Voropaev et al. This article is distributed under the terms of the Creative Commons Attribution License, which permits unrestricted use and redistribution provided that the original author and source are credited.

Selection and Peer-review under the responsibility of The Ural school-seminar of metal scientists-young researchers Conference Committee.

\section{G OPEN ACCESS} subjected to the process. The thickness of the layer that had a microhardness of $\geq 600 \mathrm{HV}_{0,05}$ turned out to be about $0,75 \mathrm{~mm}$ while the microstructure of the hardened layer was martensitic, martensitic and perlitic with dispersed inclusions of carbides. It was established that the feed has the biggest influence on the thickness of the hardened layer.

Keywords: friction stir processing, rotation speed, tool feed, normal force, microhardness, microstructure.

\section{Intorduction}

Friction stir processing with a rotating tool (FSP) is based on controlling intensive localized plastic deformation and high-speed thermal effect. FSP is applied for processing alloys containing aluminum, magnesium, copper, steels, etc. To control the FSP process the following variables are distinguished: tool rotating speed, feed and axial force [1. FSP normally employs a tool with a shoulder and a tip because of which various defects are likely to occur in the surface layer. To avoid internal defects tools with no tip but with a flat end face and a chamfer [3] are used. A kinematic diagramme illustrating FSP is presented in Figure 1.

The paper [4] gives results of researching into FSP for the case of processing AISI 420 steel. It was determined that hardening of the surface layer is achieved through forming 


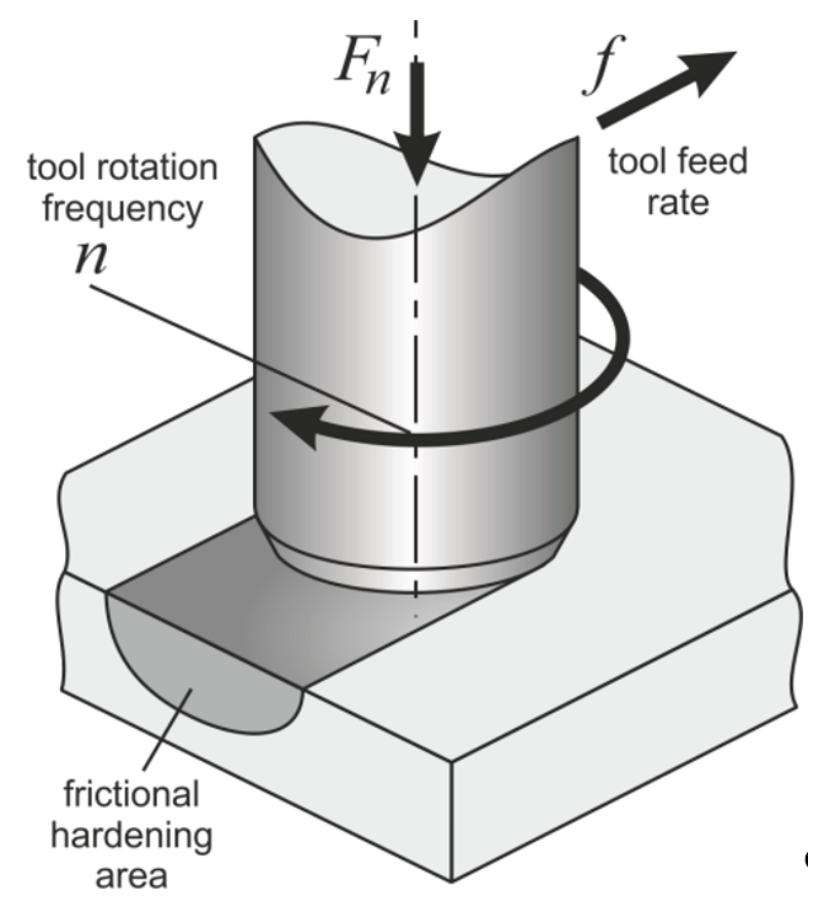

Figure 1: Kinematic diagramme of friction stir processing.

a martensitic structure. Strengthening surface layers in chromium steels by FSP with a tool that has a flat end face under the conditions when the effect of stirring is reduced to a minimum can be done predominantly by thermal action, through air hardening.

In this particular case it is essential that the surface layer should be heated to a temperature $\left(T_{n}\right)$ exceeding the critical point $A c_{3}=950^{\circ} \mathrm{C}$ and pearlite be transformed into austenite.

To attain optimal results of hardening AISI 420 steel it is necessary to establish the impact of FSP variables on the structure and properties of the surface layer.

The selected process variables are expected to ensure heating to reach the temperature $\mathrm{T}_{n}>\mathrm{Ac}_{3}$ and an appropriate conditioning time $\mathrm{t}_{\text {cond }}$ at this temperature to transfer the friction heat to the surface layer. At the same time, overheating of the material must be avoided as in this case austenite grains will significantly grow in size which is likely to adversely affect strength, hardness and other mechanical properties.

Thus, proper process modes should be selected so that the $\alpha \rightarrow \gamma$ transformation could be ensured avoiding austenite grain growth. Analyzing a correlation between process variables and thermal parameters has made it possible to present it as a diagramme of hardening control (fig. 2). 


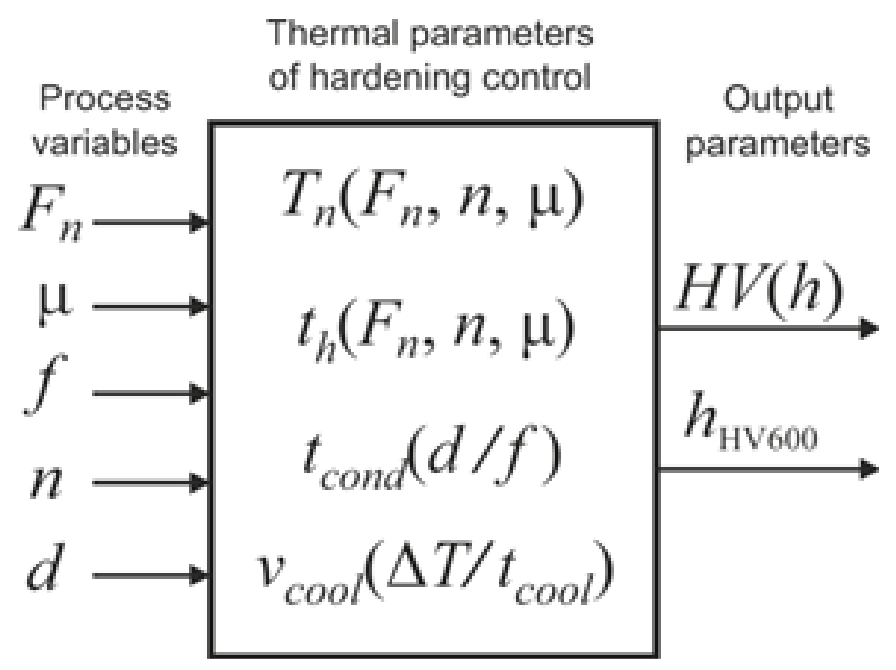

Figure 2: Diagramme showing hardening control.

\section{Experimental Setup}

The friction stir processing was conducted on a MA-600/Okuma milling machine centre making use of 100-mm diameter samples fabricated from AISI 420 steel, the original hardness being $187 \mathrm{HB}$ while the microhardness after milling was $220-230 \mathrm{HV}_{0,05}$. FSP was done with a Iskar tungsten carbide based hard-alloy tool with a flat end face end; the diameter of its body was $9 \mathrm{~mm}$ and its chamfer $-0,5 \times 45^{\circ}$. The process variables are shown in table 1.

TABLE 1: The process variables.

\begin{tabular}{|l|c|c|c|}
\hline № exp. & $F_{n},[\mathrm{~N}]$ & $f,[\mathrm{~mm} / \mathrm{min}]$ & $n,[\mathrm{rev} / \mathrm{min}]$ \\
\hline 1 & 2500 & 100 & 3000 \\
\hline 2 & 2500 & 150 & 3500 \\
\hline 3 & 2500 & 200 & 4000 \\
\hline 4 & 3000 & 100 & 3500 \\
\hline 5 & 3000 & 150 & 4000 \\
\hline 6 & 3000 & 200 & 3000 \\
\hline 7 & 3500 & 100 & 4000 \\
\hline 8 & 3500 & 150 & 3000 \\
\hline 9 & 3500 & 200 & 3500 \\
\hline
\end{tabular}




\section{Results and Discussions}

Metallographic samples were prepared to measure the microhardness of the surface layer at various depths after FSP. The plane lay at a $19^{\circ}$-degree angle in reference to the treated surface. Microhardness measurements were made along the central axis of each track by Vickers hardness test making use of a Leica VMHT microhardness tester with a $50 \mathrm{gf}$ load applied on the indentor. $\mathrm{HV}_{0,05}$ microhardness was measured along the depth with $10 \mu \mathrm{m}$ incremental steps to the depth of $50 \mu \mathrm{m}$, with a $20 \mu \mathrm{m}$ incremental step to the depth of $50 \mu \mathrm{m}$, a $50 \mu \mathrm{m}$ step to the depth of $900 \mu \mathrm{m}$ and a $100 \mu \mathrm{m}$ step until the parent matrix was reached. 5 measurements were made at each depth.

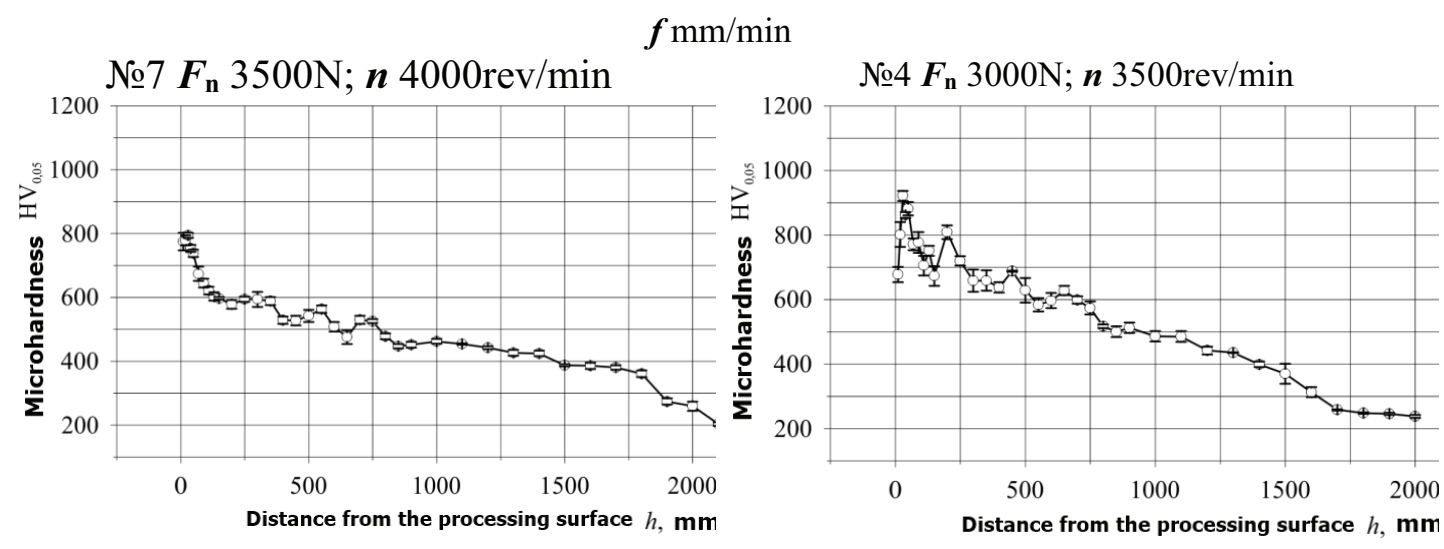

Figure 3: Changing of microhardness in depth.

The microhardness tests (fig. 3) showed that the deepest hardened layer of approximately $1,7 \mathrm{~mm}$ was obtained in sample №4 treated at $\mathrm{F}_{n}=3000 \mathrm{~N}: \mathrm{f}=100 \mathrm{~mm} / \mathrm{min}: \mathrm{n}=3500$ $\mathrm{rev} / \mathrm{min}$; and №7 produced at $\mathrm{F}_{n}=3500 \mathrm{~N}: \mathrm{f}=100 \mathrm{~mm} / \mathrm{min} ; \mathrm{n}=4000 \mathrm{rev} / \mathrm{min}$. Both modes have the slowest feed. This indicates that the feed is an important factor affecting not only the hardness but also the depth of the hardened layer. One more criterion of hardening the surface layer may be its thickness with a microhardness of $\geq 600 \mathrm{HVO}, 05$. The best treatment mode according to this criterion was used in experiment №4 when the thickness of the layer with a microhardness of $\geq 600$ HVO, 05 was approximately $0,75^{\circ} \mathrm{mm}$. Studying the microstructure of the working zone was done on an OLYMPUS optical microscope using SIAMS-700 software and x50 and x500 magnification. A postFSP mictrostructural analysis of the surface layer showed the formation of a zone of parabolic shape where the modified mictrostructure is observed (fig. 4). In this zone 3 areas emerge. In area 1 next to the treated surface, a martensitic structure with dispersed inclusions of carbides can be seen (fig 5, a). A microstructural analysis at a depth of 500 $\mu \mathrm{m}$ showed that the formation of a homogeneous martensitic structure is ensured only 
if the feed is $100 \mathrm{~mm} / \mathrm{min}$ (fig. 5, b). At $1000 \mu \mathrm{m}$ from the surface and $100 \mathrm{~mm} / \mathrm{min}$ feed a composite martensitic-perlite structure with dispersed inclusions of carbides is formed (fig. 5, c). When the feed values are 150 and $200 \mathrm{~mm} / \mathrm{min}$, at a depth of $1000 \mu \mathrm{m}$ no changes in the microstructure occur

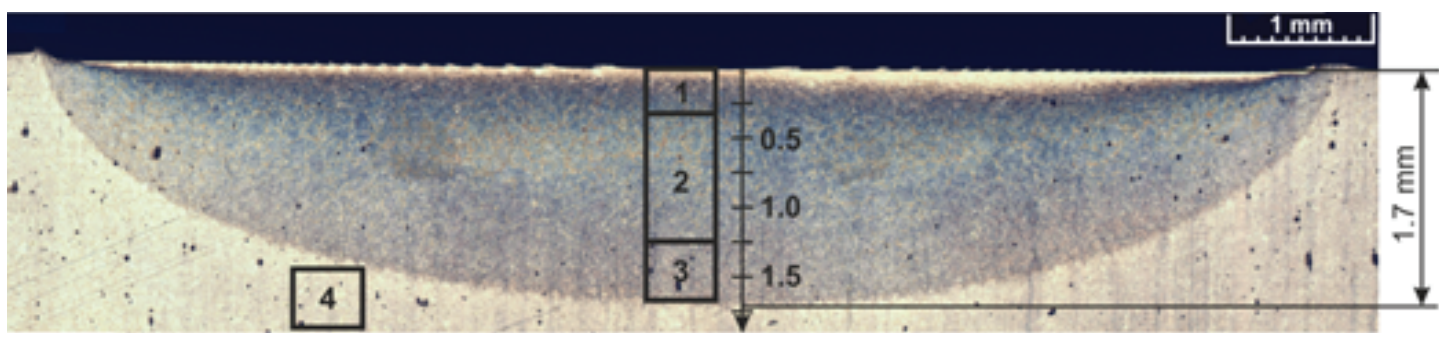

Figure 4: Microstructure of the surface layer at x50 magnification of experiment №4.

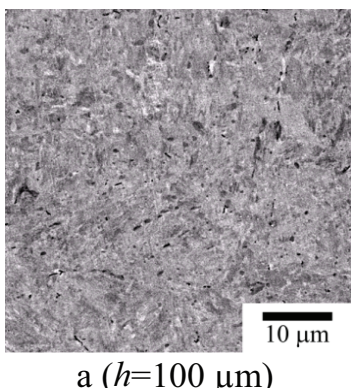

a $(h=100 \mu \mathrm{m})$

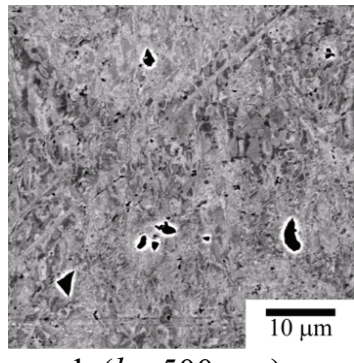

$\mathrm{b}(h=500 \mu \mathrm{m})$

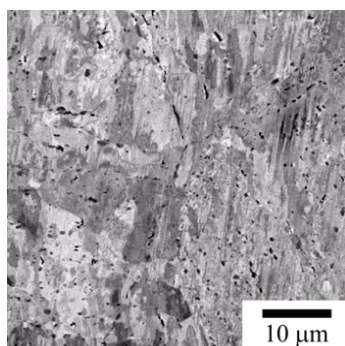

c $(h=1000 \mu \mathrm{m})$

Figure 5: Microstucture of a hardened layer at $\times 500$ magnification $F=3000 \mathrm{~N} ; f=100 \mathrm{~mm} / \mathrm{min} ; n=$ $3500 \mathrm{rev} / \mathrm{min}$.

\section{Conclusions}

Comparing the microstructure measurements and the microstructural analysis of the modified and original materials together with the temperature changes in the FSP at various combinations of process variables gives grounds to draw the conclusion that the conditioning time at maximum temperature has a decisive influence on the thickness of the hardened layer.

\section{References}

[1] Mishra R.S., Ma Z.Y. Friction stir welding and processing/ R.S. Mishra, Z.Y. Ma // Materials Science and Engineering R 50 (2005) 1-78; doi:10.1016/j.mser.2005.07.001.

[2] Rai R. Review: friction stir welding tools/ R. Rai, A. De, H. K. D. H. Bhadeshia and T. DebRoy// Science and Technology of Welding and Joining, 2011. 
[3] Zhang Y. N. Review of tools for friction stir welding and processing / Y. N. Zhang, X. Cao, S. Larose and P. Wanjara // Canadian Metallurgical Quarterly, 2012.

[4] Dodds S. Tribological enhancement of AISI 420 martensitic stainless steel through friction-stir processing/ S. Dodds, A.H.Jones, S.Cater // Wear, 2013; dx.doi.org/10.1016/j.wear.2013.01.007i. 